\title{
Parental Awareness About School Backpack, Weight Carried by Their Children and related Musculoskeletal Problems
}

\author{
Gita Dhakal Chalise', Samjhana Sherpa ${ }^{2}$, Mamata Bharati ${ }^{1}$ and Ambu KC ${ }^{1}$
}

${ }^{1}$ College of Nursing, Nepalese Army Institute of Health Sciences, Sanobharyang, Kathmandu, Nepal

${ }^{2}$ Nidan Hospital, Pulchowk, Lalitpur, Nepal

\begin{abstract}
Introduction: Backpacks are a convenient means to carry essential educational materials for school children. Backpack design, carrying technique and its load is related to several health consequences i.e., altered gait, bad posture and musculoskeletal pain. Parental awareness and their supervision can help their children to carry appropriate school backpack with rationale weight. Therefore, this study aims to assess parental awareness about school backpacks; identify backpack weight carried by their children and identify children's musculoskeletal complaints with their parents.

Methods: A descriptive cross-sectional study design was used. The study consisted of purposively selected 94 parents whose children were studying in grade VI to VIII at local school. Face to face interview of around 30 minutes duration was taken by using semi structured interview schedule. Backpack weight was identified by weighing children with and without bag in their school and subtracted to identify the actual backpack weight. Data was analysed by using SPSS version 20 and described by using descriptive statistics.

Results: In this study, more than $90 \%$ parents were aware of the recommended weight of school backpack i.e., $<15 \%$ of body weight. About $96 \%$ parents answered that backpack should be light; similar percentage told that it should have well-padded shoulder straps and $87 \%$ answered that it should be appropriate to child's age and weight. Around $70 \%$ to $90 \%$ parents were aware of appropriate handling of school backpacks. While identifying parental awareness about musculoskeletal effects of backpacks, they told as shoulder pain (79\%), fatigue $(76 \%)$ and neck pain $(56 \%)$. In this study, $72 \%$ children were carrying backpacks greater than the recommended weights. Their parents told that children often had complaints of shoulder pain (78\%) and neck pain $(69 \%)$

Conclusions: Most parents were aware of the standards and handling of school backpack but in reality, more than two third of their children were carrying heavy school backpacks.

Key words: school backpack; parental awareness; musculoskeletal problems; recommended weight; shoulder straps; neck pain; foot pain; fatigue
\end{abstract}

Correspondence: Gita Dhakal Chalise, Nepalese Army Institute of Health Sciences, College of Nursing, E-mail: gita.dhakal@gmail.com.

DOI: http://dx.doi.org/10.3126/mjsbh.v19i2.28321

Submitted on: $2020-04-04$

Accepted on: 2020-05-12 


\section{INTRODUCTION}

Backpack represents a common consumer product in our modern school system and becomes the most popular means of carrying belongings to and from school. Several organisations recommend that backpacks weigh no more than $10 \%-20 \%$ of the student's body weight, ${ }^{1-3}$ Similarly, other studies also recommended that the weight of the school bag should be $10 \%$ to $15 \%$ of the body weight. With daily carriage of excessive loads by school children in their school bags, they can develop various musculoskeletal problems i.e. lower and upper back pain, shoulder pain and neck pain..$^{4-6}$ Heavy schoolbags and their adverse musculoskeletal effects are a cause of great concern. ${ }^{7}$ Parental awareness about this issue is crucial to prevent such health problems in their children.

The overloaded, improper or improperly worn backpack causes physical stresses to children, which cause significant forward lean of the head and trunk. This daily discontinuous postural adaptation is associated with pain and disability among children. ${ }^{8}$ American Occupational Therapy Association (AOTA) identified certain characteristics of backpack safety which includes loading and wearing a backpack. ${ }^{9}$ When purchasing a backpack, many parents probably give little or no attention to backpack design, padding and overall weight. They also might not be aware of the recommended backpack weight, lifting, carrying or wearing backpack correctly. Parents are the key person to provide standard schoolbags in terms of weight, size, straps, and waist support to their children and monitor how they carry the schoolbag and for how long. They can also identify the early symptoms such as pain or abnormal posture in their children and consult medical professionals. ${ }^{10}$ Therefore parental awareness helps in purchasing safe schoolbags for their children and reducing the loads carried by them.

In the context of Nepalese education system, we can observe that children are carrying heavy schoolbags daily. ${ }^{11}$ This should be a major concern for parents as well as stakeholders. But there are limited published studies regarding this issue in Nepal. Therefore, this study was conducted to assess parental awareness about school backpack, weight carried by their children and related musculoskeletal problems. Findings of this study might be helpful to plan and provide health education to parents and other stakeholders about standards of school backpack and safe handling of this product in that area. This measure might be helpful to reduce backpack related problems among school children by selecting safe school backpacks, supervising, carrying and checking backpack weight regularly.

\section{METHODS}

The study was conducted at Hetauda Municipality ward number nine among purposively selected 94 parents whose children were studying at grade VI to VIII and carrying school backpack by children themselves. Initially all students from grade VI to VIII were identified from local private school. In school, researcher measured their weight with and without bag and subtracted to identify the actual weight of school bag. The contact address of their parents was collected from the students. From this, researcher identified the study sample (parents). Then face to face interview was taken with each parent by researcher herself. Only one parent either mother or father whoever present during the time of data collection and whose children was carrying backpacks by their own were included in the study. It was taken about 20-30 minutes to complete the interview session.

After an extensive literature review, semistructured interview schedule (later called as instrument) was developed by researcher. The schedule consisted of two parts. First part consisted of socio demographic information, parental awareness regarding standards and handling of school backpack and related musculoskeletal problems, and their children's musculoskeletal complaints. Awareness questions contained correct as well as incorrect responses. Second part consisted of instrument to measure child's weight and school bag weight. Initially instruments were developed in English and translated into Nepali for better understanding and back translation was done to determine its correctness. Before data collection, research instrument was pretested among 10 parents who were not involved in the main study. The research instrument was revised and finalised on the basis of the results of pretest. SPSS version 20 for windows was used for data analysis. 
Ethical approval was obtained from Institutional Review Committee of our institution. Written permission for data collection was taken from Hetauda Municipality ward number 9 office and school. Informed written consent was obtained from each parent before data collection. Other ethical principles were also applied during the whole process of the study.

\section{RESULTS}

The mean age of parents was 34.74 years $(\mathrm{SD} \pm$ 3.830 ); female (84\%); from nuclear family (54.3\%) and house managers (34\%). More than half (52.1\%) of their children used to walk 11-20 minutes carrying backpacks themselves while going to school.

In this study, $54 \%$ of parents answered that the weight of the school backpack should be less than $10 \%$ of the body weight and $38 \%$ answered that it should be $10 \%$ to $15 \%$ of body weight (Table 1 ).

Most of the parents had given correct responses regarding characteristics of school backpack i.e., lightweight backpack (95.7\%), backpack with wellpadded shoulder straps $(95.7 \%)$ and size of the backpack should fit for child's age and weight (87.2\%). They had also given incorrect responses on backpack characteristics i.e., backpack with abdominal straps (55.3\%) and heavy backpack (10.6\%) (Table 2).

While asking about the handling of school backpack, they told that shoulder straps should be firm and sufficiently fastened (89.4\%), always use both shoulder straps on the backpack (88.3\%) and wear a backpack at waist level (79.8\%) which were correct responses. Incorrect responses given by them were: straps of the backpack should be loose $(34 \%)$ and wear a backpack low on the back (16\%) (Table 3).

Table 1. Awareness of parents regarding recommended weight of school backpack

\begin{tabular}{l|lr|}
$\begin{array}{l}\text { Recommended weight of } \\
\text { school backpack }\end{array}$ \\
\hline$<10 \%$ of body weight & 51 & 54.3 \\
10 to $15 \%$ of body weight & 36 & 38.2 \\
15 to $20 \%$ of body weight & 6 & 6.4 \\
$>20 \%$ of the body weight & 1 & 1.1 \\
Total & 94 & 100 \\
\hline
\end{tabular}

Table 2. Awareness of Parents regarding Characteristics of School Backpack $(n=94)$

\begin{tabular}{l|lr}
\hline * Characteristics & Frequency & $\%$ \\
\hline Lightweight backpack\# & 90 & 95.7 \\
$\begin{array}{l}\text { Backpack with well-padded } \\
\text { shoulder straps\# }\end{array}$ & 90 & 95.7 \\
$\begin{array}{l}\text { Size of the backpack should fit } \\
\text { for child's age and weight\# }\end{array}$ & 82 & 87.2 \\
$\begin{array}{l}\text { Backpack with wide shoulder } \\
\text { straps\# }\end{array}$ & 72 & 76.6 \\
$\begin{array}{l}\text { Padding at the rear of the } \\
\text { backpack which comes into } \\
\text { contact with the back and } \\
\text { shoulders\# }\end{array}$ & 69 & 73.4 \\
$\begin{array}{l}\text { Backpack with waist straps\# } \\
\text { Backpack with abdominal straps }\end{array}$ & 52 & 67 \\
$\begin{array}{l}\text { Heavy backpack } \\
\text { Backpack with thin clothing } \\
\text { straps }\end{array}$ & 7 & 55.3 \\
\hline
\end{tabular}

* Multiple Responses \#Correct Response

In this study, $79 \%$ parents told that inappropriate handling of school backpack causes shoulder pain. Others answered that it causes fatigue (75.5\%), neck pain (56.4), upper back pain (30.9\%), low back pain (29.8\%) and foot pain (26.6\%) (Table 4).

Table 3. Awareness of parents about handling of school backpack

\begin{tabular}{|c|c|c|}
\hline *Handling & Frequency & $\%$ \\
\hline $\begin{array}{l}\text { The shoulder straps should be } \\
\text { firm and sufficiently fastened\# }\end{array}$ & 84 & 89.4 \\
\hline $\begin{array}{l}\text { Always use both shoulder } \\
\text { straps on the backpack\# }\end{array}$ & 83 & 88.3 \\
\hline $\begin{array}{l}\text { Always wear a backpack at } \\
\text { waist level \# }\end{array}$ & 75 & 79.8 \\
\hline $\begin{array}{l}\text { Choose a backpack with } \\
\text { adjustable padded shoulder } \\
\text { straps and a padded back } \\
\text { panel\# }\end{array}$ & 64 & 68.1 \\
\hline $\begin{array}{l}\text { Straps of the backpack should } \\
\text { be loose }\end{array}$ & 32 & 34.0 \\
\hline $\begin{array}{l}\text { Put heaviest items closest to } \\
\text { your back\# }\end{array}$ & 55 & 58.5 \\
\hline $\begin{array}{l}\text { It is better to wear a backpack } \\
\text { low on your back }\end{array}$ & 15 & 16.0 \\
\hline $\begin{array}{l}\text { Sling backpack with one strap } \\
\text { on one shoulder }\end{array}$ & 5 & 5.3 \\
\hline
\end{tabular}


Table 4. Awareness of Parents regarding Musculoskeletal Effects of School Backpack ( $n=94)$

\begin{tabular}{l|lr} 
*Effects & Frequency & $\%$ \\
\hline Shoulder pain & 74 & 78.7 \\
Fatigue & 71 & 75.5 \\
Neck pain & 53 & 56.4 \\
Upper back pain & 29 & 30.9 \\
Low back pain & 28 & 29.8 \\
Foot pain & 25 & 26.6 \\
Hand and wrist pain & 11 & 11.7 \\
Thigh pain & 11 & 11.7 \\
Elbow pain & 5 & 5.3 \\
\hline
\end{tabular}

*Multiple Responses \#Correct Response

This study identified that $22.3 \%$ of children had carried the school backpack with 10 to $15 \%$ of body weight whereas $34 \%$ had carried the school backpacks with $>20 \%$ of their body weight (Table 5).

While identifying children's musculoskeletal complaints with parents, most had told that their children had often complained of shoulder pain (78\%), neck pain (69\%) and foot pain (50\%) (Table $6)$.

\section{DISCUSSION}

This study investigated parental awareness regarding schoolbags and related health issues. In this study, $96 \%$ of parents were aware of the weight of the backpack that should be light but in actual practice, $72 \%$ of their children were carrying heavy backpack more than $15 \%$ of their body weight. We

Table 6. Children's musculoskeletal complaints after school

\begin{tabular}{l|cc|}
\multicolumn{1}{c}{ * Complaints } & Frequency & Percentage \\
\hline Shoulder pain & 73 & 77.7 \\
Neck pain & 65 & 69.1 \\
Foot pain & 47 & 50.0 \\
Upper back pain & 34 & 36.2 \\
Low back pain & 34 & 36.2 \\
$\begin{array}{l}\text { Hand and wrist } \\
\text { pain }\end{array}$ & 10 & 10.6 \\
Knee pain & 5 & 5.3 \\
\hline
\end{tabular}

*Multiple Responses \#Correct Response
Table 5. Backpack weight carried out by children in proportion to their body weight

\begin{tabular}{|l|l|r|}
\hline Backpack Weight & Frequency & \multicolumn{1}{c}{$\%$} \\
\hline$<10 \%$ of body weight & 5 & 5.3 \\
10 to $15 \%$ of body weight & 21 & 22.3 \\
15 to $20 \%$ of body weight & 36 & 38.4 \\
$20 \%$ of the body weight & 32 & 34.0 \\
Total & 94 & 100 \\
\hline
\end{tabular}

identified that there is wide gap existing between parental awareness and actual practice on the safe weight of schoolbags. This study identified high awareness on backpack weight but similar study conducted among 616 Saudi Arabian parents identified that only $37.6 \%$ fathers and $28.9 \%$ mothers knew the ideal weight of the schoolbag. ${ }^{7}$ Another study conducted among 586 Iranian schoolchildren aged 12 to 14 years identified that the average load carried by them was $2.8 \mathrm{~kg}$ only but our current study identified it as $7 \mathrm{~kg} .{ }^{5}$ This study clearly indicates that awareness cum knowledge should be translated into practice. If their parents are aware of this backpack issue, they can regularly check their child's backpack weight and remove unnecessary contents or purchase wheeled backpack so that their children can carry it easily.

Based on different epidemiological, physiologic and biomechanical data, the suggested weight limit of school bag is about $10-15 \%$ of children's body weight. ${ }^{4}$ In one study conducted in Northern California, the use of $10 \%$ of body weight cutoff is recommended for safe use of backpacks for all grade levels. ${ }^{12}$ But in the present study, around 28\% children had carried the school backpack with recommended weight whereas $72 \%$ had carried heavy school backpacks. This finding is supported by many other studies. The study conducted in Bangalore India among 22 school going children identified that all children had carried heavier backpack than the recommended weight. ${ }^{13}$ This finding is also supported by an article published in Himalayan Times on May 22, 2016 where V grade and VIII grade students from one private school of Kathmandu carried heavy schoolbags weighing on average eight kilos daily. School had prescribed 13 textbooks to them including reference books and carried eight books with two exercise books for 
each subject on school days and some reference books on teachers' requests on some days. ${ }^{11}$ As reported in various studies, children from other countries also used to carry heavy schoolbags. ${ }^{15,16}$ A school bag weighing more than $15 \%$ to $20 \%$ of a child's weight is associated with musculoskeletal pain, and improper use of the backpack can result in changes of posture and gait. ${ }^{14}$ Many other studies identified similar consequences. ${ }^{17,18}$ All these studies give us insight that carrying heavy school backpack is common around the globe. This is actually our education system which enforces children to carry heavier loads and puts them at risk for many actual and potential health consequences. Therefore awareness to parents is essential and it must be focused on checking the school backpack daily and removing extra items from school backpack to make it lighter. In this issue, teachers also need awareness, so that they can recommend school administration to provide locker facility to save excess books rather than carrying home every day.

In overall, present study identified good parental awareness on characteristics of healthy school backpack and appropriate handling of this product. Similar studies conducted in Iran and Maharashtra India also support these findings. ${ }^{10,19}$ Talking about awareness only, this seems quite good finding. During study, we hadn't checked their backpack type and quality therefore we can't say which type of product they were using and whether it is safe or not. But we can assume that if parents are aware of this, they can choose safe backpack for their children, teach them the correct way to carry the schoolbag on their shoulders, and monitor any adverse effects such as back or shoulder pain.

Present study identified that more than three fourth of parents were aware of the common musculoskeletal effects of heavy backpack i.e., shoulders pain $(79 \%)$ and fatigue $(76 \%)$. Other parents answered that neck pain (56\%), upper back pain $(31 \%)$ and lower back pain $(30 \%)$ as common effects. Studies conducted in Egypt and Malaysia regarding parental awareness also identified similar results. In Egypt, parents answered that low back pain $(76.4 \%)$, shoulders pain $(52.8 \%)$ and fatigue $(24.5 \%)$ as common musculoskeletal effects. ${ }^{15}$ Similarly in Malaysia, parents answered that neck pain $(24.9 \%)$, back pain $(24.6 \%)$, knee pain $(51.9 \%)$ and shoulders pain $(34.5 \%)$ as common problems. ${ }^{20}$ While asking about children's complaints with their parents, present study identified that their children often complained of shoulder pain (78\%), neck pain $(69 \%)$, foot pain (50\%), upper back pain (36\%) and lower back pain $(36 \%)$. These problems were documented on the basis of parent's responses and might not be always associated with backpack use only.

Parental awareness can help their children to carry safe school backpack with recommended weight who are not informed enough about choosing their backpack carefully and carrying it correctly. As primary advocates for their children's health, parents may play significant role to reduce the possible negative effect of carrying heavy loads and mishandling it by supervising the use of schoolbags.

\section{CONCLUSIONS}

In this study, parents are aware of the backpack weight, its characteristics, handling technique and possible health effects but in reality, more than two third of their children are carrying heavy schoolbags. It is essential that their knowledge should be translated into practice. For this, children, parents and teachers should be educated about the characteristics of safe backpack by using different strategies. These strategies may help to reduce the prevalence of musculoskeletal health problems among children.

To cite this article: Chalise GD, Sherpa S, Bharati M, KC A. Parental awareness about school backpack, weight carried by their children and related musculoskeletal problems . MJSBH. 2020;19(2):97-102.

Conflict of Interest: None declared

\section{REFERENCES}

1. Bethesda, MD. How heavy is your child's backpack? American Occupational Therapy Association (AOTA); Sept 13, 2018. Available from: https://www.aota.org/Publications-News/ForTheMedia/PressReleases/2018/091318-HowHeavy-Backpack.aspx 
2. Reuters. Is your child's backpack making the grade? Health News. August 31, 2007. Available from: https:// www.reuters.com/article/us-backpack/is-your-childs-backpack-making-the-grade-idUSCOL06600120070830

3. American Academy of Paediatrics. Back to school tips on getting the year off to a good start-from the American Academy of Paediatrics. 2019. Available from: https://www.aap.org/en-us/about-the-aap/aap-press-room/newsfeatures-and-safety-tips/Pages/ Back-to-School-Tips-Getting-the-Year- Off-to-a-Good-Start-from-the-AAP.aspx

4. Brackley HM, Stevenson JM. Are children's backpack weight limits enough? A critical review of the relevant literature. Spine. 2004;29(19):2184-90. DOI: 10.1097/01.brs.0000141183.20124.a9.

5. Dianat I, Sorkhi N, Pourhossein A, Alipour A, Asghari-Jafarabadi M. Neck, shoulder and low back pain in secondary schoolchildren in relation to schoolbag carriage: should the recommended weight limits be genderspecific? Appl Ergon. 2014;45(3):437-42. DOI: 10.1016/j.apergo.2013.06.003.

6. Skaggs DL, Early SD, D'Ambra P, Tolo VT, Kay RM. Back pain and backpacks in school children. J Pediatr Orthop. 2006;26(3):358-63. DOI: 10.1097/01.bpo.0000217723.14631.6e

7. Abdulmonem A, Raheef A, Fayez NA, Khalid B, Waleed A, Abdulrahman A, et al. Assessment of perceptions, knowledge, and attitudes of parents regarding children's schoolbags and related musculoskeletal health. J Orthop Surg Res. 2019;14:113. DOI: 10.1186/s13018-019-1142-9.

8. Rai A, Aggrawal S. Back problems due to heavy backpacks in school children. IOSR-JHSS. 2013;10(6):22-26. eISSN: 2279-0837, p-ISSN: 2279-0845

9. American Occupational Therapy Association. Backpack strategies for parents and students. 2020. Available from: https://www.aota.org/About-Occupational-Therapy/Patients-Clients/ChildrenAndYouth/Backpack-StrategiesParents-Students.aspx

10. Javadivala Z, Allahverdipour H, Dianat I, Bazargan M. Awareness of parents about characteristics of a healthy school backpack. Health Promot Perspect. 2012;2(2):166-172. DOI: 10.5681/hpp.2012.019

11. KC K. Children overburdened with heavy schoolbags. The Himalayan Times. May 22, 2016. Available from: https://thehimalayantimes.com/kathmandu/children-overburdened-heavy-schoolbags/

12. Moore MJ, White GL, Moore DL. Association of relative backpack weight with reported pain, pain sites, medical utilization and lost school time in children and adolescents. J Sch Health. 2007;77(5):232-9. DOI: 10.1111/j. 1746-1561.2007.00198.x

13. Sharan D, Ajeesh PS, Jose JA, Debnath S, Manjula M. Backpack injuries in Indian school children: risk factors and clinical presentations. Work. 2012;41(1):929-32. DOI: 10.3233/WOR-2012-0265-929.

14. Mackenzie WG, Sampath JS, Kruse RW, Sheir-Neiss GJ. Backpacks in children. Clin Orthop Relat Res. 2003; (409):78-84. DOI: 10.1097/01.blo.0000058884.03274.d9

15. EI Magrabi NM, Mahmoud SR, El-Sayed Yousef Y. Awareness of parents about school backpack and its related musculoskeletal disorders in Assiut city. IOSR-JNHS. 2015;4(6):5-11. DOI: 10.9790/1959-04650511

16. Negrini S, Carabalona R, Sibilla P. Backpack as a daily load for schoolchildren. Lancet. 1999;354(9194):1974. DOI: 10.1016/S0140-6736(99)04520-1

17. Spiteri K, Busuttil ML, Aquilina S, Gauci D, Camilleri E, Grech V. Schoolbags and back pain in children between 8 and 13 years: a national study. BJP. 2017;11(2):81-6. DOI: 10.1177/2049463717695144

18. Ghousia S, Khalid A, Abida A, Muhammad FF. Prevalence of musculoskeletal pain due to heavy backpacks in school going children of Karachi. Int J Phys Med Rehabil. 2018;6(3):1000471. DOI:10.4172/2329-9096.1000471.

19. Patil MA, Sumana S, Shagale N. Awareness of parents about characteristics and carrying habits of backpack and its comparison with behavioral practices of their children. Ped Rev: Int J of Ped Res. 2016;3(3). DOI: https://doi.org/ 10.17511/ijpr.2016.103.07.

20. Soh KG, Ghiami Z, Khallaghi K, Soh KL. Weight of backpack and muskuloskeletal pain among Iranian elementary school students. Int J Acad Res Bus Soc Sci. 2017;7:1012-21. DOI: 10.6007/IJARBSS/v7-i14/3757 